\title{
Patient-derived endothelial progenitor cells improve vascular graft patency in a rodent model
}

\author{
J.D. Stroncek ${ }^{\mathrm{a}, 1}$, L.C. Ren ${ }^{\mathrm{b}, 1}$, B. Klitzman ${ }^{\mathrm{a}, \mathrm{b}}$, W.M. Reichert ${ }^{\mathrm{a}, *}$ \\ a Department of Biomedical Engineering, Duke University, Durham, NC 27708, USA \\ ${ }^{\mathrm{b}}$ Kenan Plastic Surgery Research Labs, Duke University, Durham, NC 27708, USA
}

\section{A R T I C L E I N F O}

\section{Article history:}

Received 23 June 2011

Received in revised form 23 August 2011

Accepted 1 September 2011

Available online $\mathrm{xxxx}$

\section{Keywords:}

Synthetic vascular graft

ePTFE

Endothelial progenitor cells

Thrombomodulin

Coronary artery disease

\begin{abstract}
A B S T R A C T
Late outgrowth endothelial progenitor cells (EPCs) derived from the peripheral blood of patients with significant coronary artery disease were sodded into the lumens of small diameter expanded polytetrafluoroethylene (ePTFE) vascular grafts. Grafts (1 mm inner diameter) were denucleated and sodded either with native EPCs or with EPCs transfected with an adenoviral vector containing the gene for human thrombomodulin (EPC + AdTM). EPC + AdTM was shown to increase the in vitro rate of graft activated protein C (APC) production 4 -fold over grafts sodded with untransfected EPCs $(p<0.05)$. Unsodded control and EPC-sodded and EPC + AdTM-sodded grafts were implanted bilaterally into the femoral arteries of athymic rats for 7 or 28 days. Unsodded control grafts, both with and without denucleation treatment, each exhibited 7 day patency rates of $25 \%$. Unsodded grafts showed extensive thrombosis and were not tested for patency over 28 days. In contrast, grafts sodded with untransfected EPCs or EPC + AdTM both had 7 day patency rates of $88-89 \%$ and 28 day patency rates of $75-88 \%$. Intimal hyperplasia was observed near both the proximal and distal anastomoses in all sodded graft conditions but did not appear to be the primary occlusive failure event. This in vivo study suggests autologous EPCs derived from the peripheral blood of patients with coronary artery disease may improve the performance of synthetic vascular grafts, although no differences were observed between untransfected EPCs and TM transfected EPCs.
\end{abstract}

(c) 2011 Acta Materialia Inc. Published by Elsevier Ltd. All rights reserved.

\section{Introduction}

In the US, about 500,000 patients undergo coronary artery bypass grafting (CABG) each year [1]. It is estimated that $15 \%$ of CABG patients are unable to undergo repeat surgeries because they lack sufficient blood vessels suitable for grafting $[2,3]$. This problem is compounded by the lack of clinically suitable small diameter ( $<6 \mathrm{~mm}$ ) synthetic vascular grafts, primarily due to unacceptable patency rates caused by luminal thrombosis and intimal hyperplasia.

The presence of a functional and intact endothelium has been shown to improve the patency of synthetic small diameter grafts $[4,5]$. However, endothelialized synthetic grafts have not received widespread adoption, in part due to difficulties with the invasive autologous sourcing of endothelial cells (ECs) [6]. EC-like cells with high proliferation potential can be isolated non-invasively from peripheral blood. Here, we have adopted the term "late outgrowth endothelial progenitor cells" (EPCs), while others have used "endothelial colony forming cells" $[7,8]$.

It has been shown previously that blood-derived EPCs isolated from patients with significant coronary artery disease (CAD)

\footnotetext{
* Corresponding author. Tel.: +1 919660 5151; fax: +1 9196605362.

E-mail address: reichert@duke.edu (W.M. Reichert).

1 Co-first authors.
}

exhibit many hallmarks of healthy endothelial cells. They can be expanded to higher densities with minimal contamination by other cell types, can maintain firm adhesion to the underlying substrate, and can reduce clot formation by releasing anti-thrombotic factors [9-11]. While short-term proof-of-principle studies have indicated that animal-derived EPCs can improve the patency rates of synthetic small diameter vascular grafts [12-14], there has been limited longer-term in vivo testing of patient-derived EPCs.

A key intrinsic mediator of vascular thromboresistance is thrombomodulin (TM), a membrane-bound glycoprotein that is central to the protein $C$ anti-coagulation pathway [15]. TM binds free thrombin to change its conformation and inhibit its pro-coagulant potential. The TM-thrombin complex then acts as a cofactor that binds with protein $C$, catalyzing its conversion to activated protein $C$ (APC). APC in turn inhibits clotting by binding protein $S$ and proteolytically cleaving two coagulation factors responsible for generating thrombin: Factor Va and Factor VIIIa $[15,16]$.

TM expression by ECs is decreased in patients with diabetes and atherosclerosis, and these patients might benefit from up-regulating their TM expression [17-19]. Autologous vein grafts with ECs overexpressing TM have previously been shown to reduce thrombosis [20,21] and decrease intimal hyperplasia [21]; however, the ability of TM overexpression to improve the performance of small diameter synthetic vascular grafts remains unknown. The purpose 
of this study was to test whether EPCs isolated from patients with CAD could reduce thrombus formation of small diameter ePTFE grafts, and whether overexpressing TM by EPCs would further increase the thromboresistance.

\section{Materials and methods}

\subsection{EPC isolation and cell culture}

All cells designated as "EPCs" in the current study were late outgrowth EPCs isolated and expanded from $50 \mathrm{ml}$ of peripheral blood drawn from patients undergoing cardiac catheterization in the Duke University Medical Center who had advanced coronary artery disease diagnosed by angiography. The Duke University Institutional Review Board approved the protocol for collection and use of human blood employed in the study.

EPCs were isolated following a protocol for isolation from cord blood [22]. Briefly, mononuclear cells were separated and plated onto collagen I coated plates and cultured in complete endothelial basal medium (EBM-2) plus endothelial growth medium (EGM-2) SingleQuots (Lonza, Walkersville, MD) with $10 \%$ fetal bovine serum (Thermo Scientific HyClone, Waltham, MA) and 1\% antibiotic/antimycotic solution (Gibco, Carsbad, CA). After $24 \mathrm{~h}$ of culture, nonadherent cells were removed and complete EGM-2 medium was added to each well. Medium was changed daily for 7 days and then every other day. EPCs were characterized previously as "EC-like" if they were positive for the EC markers CD31 and CD105 and negative for CD133, CD14 and CD45 [11]. EPCs were isolated from five patients and used at passages 5-10 (three males and two females with an average age of 56 years, range 44-69). Patient demographics have been reported previously [11].

\subsection{Adenovirus vectors}

Two different adenoviral vectors were used in this study and have been described previously [19]. Replication deficient $\beta$-galactosidase adenovirus "control vector" (AdCV) was purchased (Eton Bioscience, San Diego, CA). Replication deficient adenoviral expressing human thrombomodulin (AdTM) was a gift from Dawn Bowles, Duke University. EPCs were transfected with AdTM or AdCV for $4 \mathrm{~h}$ at $100 \mathrm{MOI}$ (multiplicity of infection) 1 day before graft sodding.

\subsection{Vascular graft conditions}

Small diameter ePTFE vascular grafts with $1 \mathrm{~mm}$ inner diameter and $30 \mu \mathrm{m}$ nominal internodal distance (International Polymer Engineering, Tempe, AZ) were used in all studies. Five vascular graft conditions were tested: (i) bare off-the-shelf ePTFE vascular grafts; (ii) denucleated grafts (grafts having air removed by immersing in $100 \%$ ethanol and drawing a vacuum until no bubbles were released from the graft); (iii) grafts sodded with native EPCs; (iv) grafts sodded with EPCs transfected with AdCV; and (v) grafts sodded with EPCs transfected with AdTM. Grafts were denucleated in all conditions that involved cell sodding.

\subsection{Graft sodding}

The graft endothelialization method used in this study was similar to that of Kidd et al. [23], where cells are "sodded" onto the porous graft lumen under positive pressure. ePTFE vascular grafts were placed in vacutainers containing $2.5 \mathrm{mg} \mathrm{ml}^{-1}$ tridodecylmethylammonium chloride (TDMAC; Polysciences, Warrington, PA), a cationic surfactant, in ethanol at room temperature. A vacuum was drawn to "denucleate" grafts by removing residual air.
Denucleation was halted when air bubbles were no longer released from the graft and the graft became translucent and sank to the bottom of the solution. Denucleation reduces material thrombogenicity [24] and TDMAC increases fibronectin adsorption on hydrophobic materials such as ePTFE [25]. The grafts were washed three times in Dulbecco's phosphate-buffered saline and incubated in a solution of human fibronectin $\left(20 \mu \mathrm{g} \mathrm{ml}^{-1}\right)$ at $37^{\circ} \mathrm{C}$ for approximately $1 \mathrm{~h}$.

Transfected and native EPCs were detached using 0.025\% tryp$\sin$ (Lonza) for approximately $10 \mathrm{~min}$ and resuspended in $5 \mathrm{ml}$ medium to achieve an effective graft luminal seeding density of $1.5 \times 10^{6}$ cells $\mathrm{cm}^{-2}$. The graft was cannulated with a 19-gauge needle and the distal end of the graft was clamped with titanium vascular clips (Teleflex medical, Research Triangle Park, NC). The cell suspension was infused into the graft at a rate of $0.5 \mathrm{ml} \mathrm{min}{ }^{-1}$ using a programmable syringe pump (Harvard Apparatus, Holliston, MA). The cell solution was flushed through the graft and cells were trapped in the graft interstices. The effluent was collected into a separate container and showed few cells, indicating that the majority of the cells were present on the graft. Following sodding, the cannula and vascular clamps were removed and the graft was placed into a 6-well plate containing EBM-2 complete medium and cultured for 2 days before in vitro or in vivo testing.

\subsection{EPC adhesion to the graft lumen}

Cell coverage on the graft was assessed after exposure to surgical clamping and super-physiological flow. Fresh EBM-2 complete medium was used to cover the graft while in the 6-well plate. Microvascular clamps (S\&T AG, Neuhausen, Switzerland) were placed at each end of the graft. Every $5 \mathrm{~min}$, the position of the clamps were adjusted along the length of the graft to simulate the suturing movements. This procedure was performed for $30 \mathrm{~min}$ and the 6 -well plate was maintained at $37^{\circ} \mathrm{C}$ using a heated stage (Pathology Devices, Westminster, MD). After $30 \mathrm{~min}$, the graft was either fixed with $3.7 \%$ paraformaldehyde (Clamped + Static) or exposed for $5 \mathrm{~min}$ to a laminar flow at 100 dynes $\mathrm{cm}^{-2}$ with a peristaltic flow setup as described above and fixed (Clamped + Flow). En face scanning electron microscopy $($ SEM) images $(1000 \times)$ were taken at four randomly selected visual fields of the graft luminal surface. Cell coverage was determined by overlaying a transparent sheet with a $10 \times 13$ uniform grid onto the micrograph and counting the percentage of grid intersection points overlying cells $(n=4)$.

\subsection{APC production}

The biological activity of EPCs sodded onto vascular grafts was assessed by measuring the rate at which protein $C$ was cleaved by the TM-thrombin complex to form APC. Grafts (length $7 \mathrm{~mm}$ ) were sodded with EPCs as described above, placed into wells of a 24-well plate and incubated with $5 \mathrm{mM}$ thrombin (Haematologic Technologies Inc (HTI), Essex Junction, VT) and $400 \mathrm{mM}$ human protein $\mathrm{C}(\mathrm{HTI})$. The rate of APC production over $1 \mathrm{~h}$ was assayed in a microtiter plate reader (BioTek Instruments, Winooski, VT) after the addition of Spectrozyme PCa (American Diagnostica, Stamford, CT), as described previously [19] $(n=4)$.

\subsection{Implantation}

The experimental protocol was approved by the Duke University Institutional Animal Care and Use Committee. Thirty-three male athymic rats, weighing 180-280 g (Charles River Laboratories, Wilmington, MA), underwent bilateral femoral artery interpositional grafting with ePTFE grafts. One of two identical grafts 
(1 $\mathrm{mm}$ diameter, $7 \mathrm{~mm}$ long and same experimental condition) was implanted into each side of the animal.

Animals were anesthetized with isoflurane in oxygen (4\% induction, then maintained with $2 \%$ to effect) and subcutaneous flunixin meglumine $\left(2 \mathrm{mg} \mathrm{kg}^{-1}\right)$. The inguinal area of the rat had the hair clipped and the skin prepared for aseptic surgery. The skin was incised, bupivacaine administered topically to the incision, the femoral sheath was exposed and the artery dissected from the vein. The femoral artery was clamped and approximately $3 \mathrm{~mm}$ of the artery was excised. A $7 \mathrm{~mm}$ length of ePTFE graft was anastomosed interpositionally using standard microsurgical technique with $10-0$ nylon interrupted sutures (Ethicon, Somerville, NJ) using an operating microscope (Olympus, OME-8000, Tokyo, Japan). The graft and surgical site was irrigated with heparinized saline $\left(12.5 \mathrm{U} \mathrm{ml}^{-1}\right)$ throughout the procedure. Once the sutures were in place the vascular clamps were released and hemostasis was achieved within 2$3 \mathrm{~min}$. Blood flow through the graft was monitored using a laser Doppler flowmeter (Laserflo BPM ${ }^{2}$ Blood Perfusion Monitor, Vasamedics, St. Paul, MN) for $30 \mathrm{~min}$ following suturing. Patency was additionally confirmed distal to the graft using a "milking test", whereby the artery distal to the graft was clamped and a section of graft further downstream was gently squeezed (i.e. milked) with loosely closed forceps to push the remaining blood distally. If the distal artery filled with blood when the proximal clamp (closest to the graft) was removed, then the graft was considered patent. No anticoagulants were administered post-operatively and pain was managed by flunixin for two additional post-operative days.

\subsection{Implant retrieval}

After 7 or 28 days, grafts were explanted. Rats were placed under general anesthesia, the inguinal skin was incised, the grafts were surgically exposed and the graft patency was evaluated by laser Doppler flowmetry and the milking test. No differences in animal behavior were observed prior to explant between animals having patent grants and those having non-patent ones. Grafts were explanted and washed in heparinized saline for 5 min, placed in $10 \%$ formalin overnight and transferred to $70 \%$ ethanol prior to paraffin embedding.

\subsection{Histology}

Tissue samples were embedded in paraffin and sectioned for histological evaluation. A series of $5 \mu \mathrm{m}$ cross-sections were obtained so that each $7 \mathrm{~mm}$ graft was visualized by at least one cross-section from the proximal, middle and distal regions. All sections were removed of paraffin using Sub-X (Surgipath Medical, Richmond, IL) and stained with hematoxylin and eosin. Additionally, Masson's trichrome staining was used to evaluate the neointimal hyperplasia of 28 day graft samples.

Sections were stained for endothelial cells after antigen retrieval with a rabbit anti-human von Willebrand Factor (vWF, 1:12,000 dilution) (Dako, Carpinteria, CA) antibody. vWF sections were incubated with a biotinylated horse anti-rabbit secondary antibody for peroxidase staining (1:200 dilution) (Vector Labs, Burlingame, CA). Human cells were distinguished after antigen retrieval though staining with mouse anti-human major histocompatibility complex class I (MHC-I) antibody (1:50 dilution) (Santa Cruz Biotechnology, Santa Cruz, CA). MHC-I staining was visualized with Alexaflour 488 goat anti-mouse secondary antibody (1:500 dilution) (Invitrogen). Sections with no primary antibody incubation served as negative controls.

Sections were imaged with a Nikon TE2000U microscope and NIS Elements software (Nikon). The luminal coverage of thrombosis and intimal hyperplasia in a given histological section were calculated, respectively, by measuring the cross-sectional area of the graft lumen occupied by the clot or intimal hyperplasia and then dividing by the total luminal cross-sectional area of the graft.

\subsection{Statistics}

Statistical differences in graft patency were assessed with Fisher's exact test. All other statistical analysis was performed with a one-way analysis of variance followed by a Tukey-Kramer post hoc test. All error bars represent the standard error of the mean. Values of $p$ below 0.05 were considered sufficient to indicate a statistically significant difference.

\section{Results}

\subsection{Graft EPC coverage}

EPCs formed a confluent cell layer uniformly covering the lumen of the small diameter vascular grafts within 2 days after sodding (Fig. 1). SEM imaging was used to characterize EPC graft coverage after grafts were exposed to conditions that mimic the mechanical manipulation during surgical implantation. EPCs were sodded onto the grafts, cultured for 2 days and observed under three conditions: after no mechanical disruption (static control), after exposure to laminar flow for 5 min (flow) and after clamping along the length of the graft for $30 \mathrm{~min}$ followed by laminar flow (clamping + flow). Flow produced a mean shear stress of 100 dynes $\mathrm{cm}^{-2}$, a magnitude 3- to 10 -fold higher than the graft would typically experience in a rat femoral artery [26].

Table 1 shows that EPCs sodded onto vascular grafts had approximately $90 \%$ graft coverage in the static control. Exposure to flow caused no significant drop in overall cell coverage vs. static conditions $(p=0.35)$. Clamping along the length of the graft with vascular clips followed by exposure to flow reduced EPC graft coverage by approximately $5 \%$. No difference in cell coverage was observed between native and transfected EPCs $(p=0.78)$.

\subsection{Activated protein $C$ production in vitro}

EPC sodding improved the anti-thrombotic bioactivity of small diameter vascular grafts as measured by the in vitro rate of graft APC production (Table 2). Grafts sodded with EPCs transfected with TM (EPC + AdTM) exhibited APC production that was greater than 10-fold higher than bare control grafts (Bare control) and 4-fold higher than both grafts sodded with native EPCs (EPC) and EPCs transfected with the control vector (EPC + AdCV). The rate of APC production between EPC and EPC + AdCV was similar, showing no detrimental effect of the adenoviral control vector on APC production.

\subsection{In vivo testing}

Bare off-the-shelf grafts (Bare Control), bare denucleated grafts (Denucleated), or denucleated grafts sodded with EPC, EPC + AdCV or EPC + AdTM were implanted bilaterally into the femoral arteries of athymic rats as described above. Upon removal of the vascular clamps, bleeding was largely limited to the anastomosis site for 1-2 min before hemostasis was achieved, with minimal weeping through the graft wall. Grafts were observed for approximately $30 \mathrm{~min}$ before closing of the surgical site to ensure successful anastomoses.

After 7 days the dominant histological feature was thrombus. Fig. 2 shows representative mid-graft histological sections of 7 day implants with extensive thrombus in bare and denucleated grafts, but limited thrombus in grafts sodded with native or transfected EPCs. No intimal hyperplasia was observed after 7 days. 

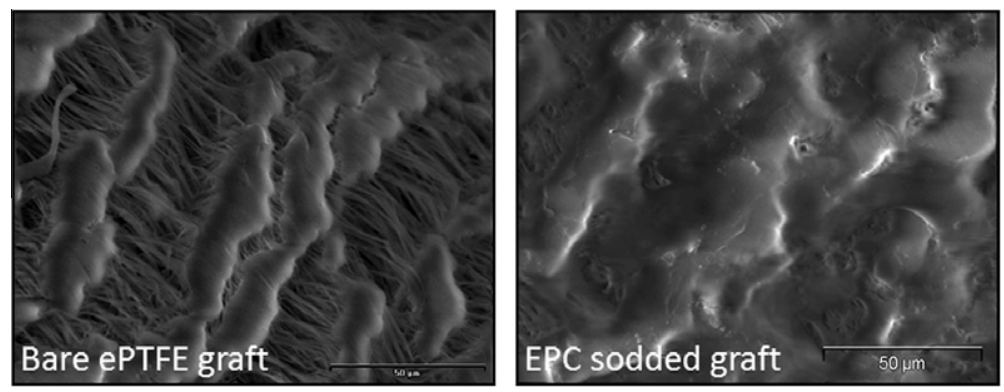

Fig. 1. EPC sodded grafts showed approximately $90 \%$ cell coverage on ePTFE grafts (scale bar $50 \mu \mathrm{m}$ ).

Table 1

Percent area of graft lumen covered by EPCs.

\begin{tabular}{llll}
\hline & EPC & EPC + AdCV & EPC + AdTM \\
\hline Static control & $88.2 \pm 2.1$ & $90.1 \pm 3.4$ & $93.0 \pm 2.4$ \\
Flow conditions & $89.1 \pm 2.4$ & $88.4 \pm 3.6$ & $88.5 \pm 1.6$ \\
Clamping + flow conditions & $87.8 \pm 2.7$ & $86.6 \pm 3.7$ & $87.4 \pm 1.5$ \\
\hline
\end{tabular}

Table 2

APC production $\left(\mathrm{nM} \mathrm{min} \mathrm{m}^{-1} \mathrm{~cm}^{-2}\right)$.

\begin{tabular}{llll}
\hline Bare control & EPC & EPC + AdCV & EPC + AdTM \\
\hline $0.07 \pm 0.01$ & $0.18 \pm 0.01^{*}$ & $0.19 \pm 0.01^{*}$ & $0.82 \pm 0.13^{*}, \#$ \\
\hline
\end{tabular}

${ }^{*} p<0.05$ vs. bare control.

\# $p<0.05$ vs. EPC and EPC + AdCV.

Fig. 3 shows the percentage of luminal cross-sectional thrombosis of grafts implanted for 7 and 28 days. The average area of thrombosis was evaluated along multiple sections for each patent graft. The presence of thrombosis was largely diminished at 28 days, with the graft response dominated instead by the presence of intimal hyperplasia. Comparing the EPC conditions, there were no significant differences in thrombus coverage at 7 days and at 28 days ( $p=0.32$ ); however, grafts sodded with EPC + AdTM had slightly less thrombus present at 7 days than native EPCs or $\mathrm{EPC}+\mathrm{AdCV}$.

\subsection{Graft patency}

Table 3 lists graft 7 day and 28 day patency rates. All unsodded grafts exhibited poor patency after 7 days and were not tested for 28 days. Sodding with native EPCs or EPCs transfected with AdTM resulted in significantly improved 7 day patency compared to bare or denucleated grafts $(p<0.05)$. Native EPCs and EPC + AdTM exhibited patency rates of $88 \%$ and $89 \%$, respectively, after 7 days, and $75 \%$ and $88 \%$ after 28 days. EPC + AdCV had patency rates of $63 \%$ after 7 days and $75 \%$ after 28 days. No significant differences were observed in 28 day patency rates between EPC and EP + AdCV

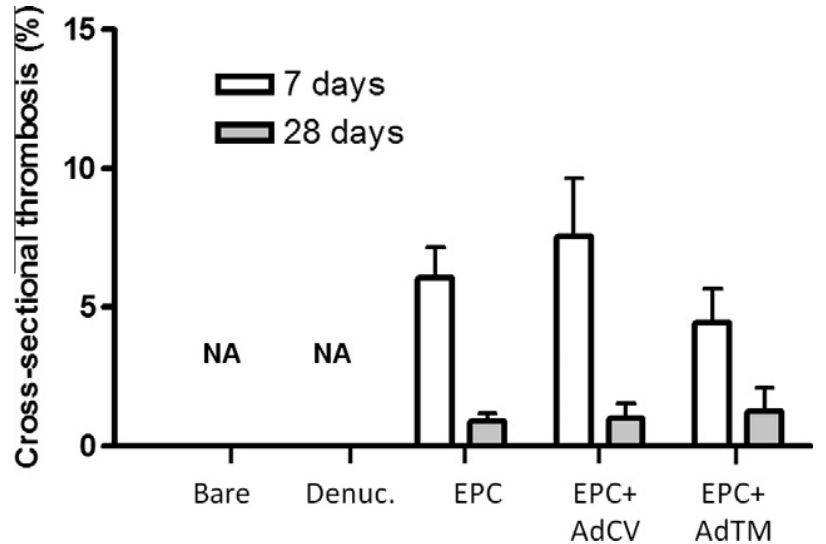

Fig. 3. Analysis of graft cross-sectional thrombosis after 7 and 28 days. Multiple cross-sections were evaluated over the length of the grafts. Only patent grafts were analyzed; therefore Bare and Denucleated grafts were not included. EPC: 7 day $(n=8), 28$ day $(n=7) ; \mathrm{EPC}+\operatorname{AdCV}: 7$ day $(n=5), 28$ day $(n=6) ; \mathrm{EPC}+\mathrm{AdTM}: 7$ day $(n=7), 28$ day $(n=6)$.

or EP + AdTM ( $p=0.91)$. Within the same animal, graft patency in one leg did not appear to affect the patency in the other leg.

\subsection{Graft intimal hyperplasia}

At 28 days the dominant histological feature of all grafts was intimal hyperplasia. Fig. 4 shows representative hematoxylin and eosin (H\&E) staining of the proximal, middle and distal regions of native and transfected EPC-sodded grafts after 28 days. All grafts showed little thrombus formation and there were no significant differences in graft cross-sectional thrombus between regions of the graft. Staining for smooth muscle cell actin revealed that the hyperplasia response consisted of smooth muscle cells (see Supplemental Fig. 1). Fig. 5 shows the percent area of 28 day graft lumens occupied by intimal hyperplasia at proximal, middle and distal positions. Hyperplasia was significantly reduced in the proximal and mid-graft regions for EPC and EPC + AdTM sodded grafts vs.

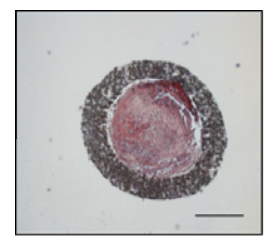

Bare Control

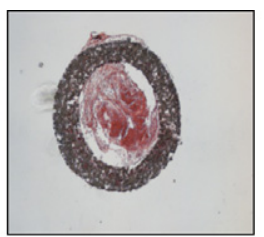

Denucleated

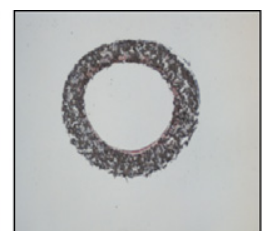

EPC

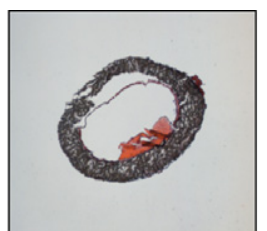

$\mathrm{EPC}+\mathrm{AdCV}$

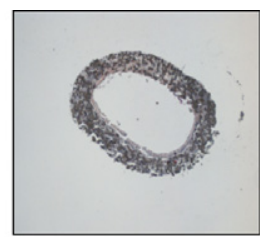

$\mathrm{EPC}+\mathrm{AdTM}$

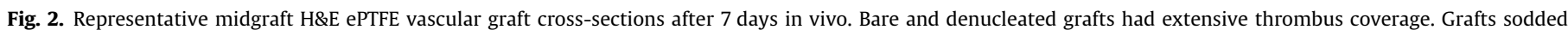
with native EPCs, AdCV EPCs, and AdTM EPCs had little thrombus present (scale bar $500 \mu \mathrm{m}$ ). 
Table 3

Graft patency rates.

\begin{tabular}{|c|c|c|c|c|c|}
\hline & Bare control & Denucleated & EPC & $\mathrm{EPC}+\mathrm{AdCV}$ & $\mathrm{EPC}+\mathrm{AdTM}$ \\
\hline 7 day patency rate & $25 \%(2 / 8)$ & $25 \%(2 / 8)$ & $89 \%(8 / 9)^{*}$ & $63 \%(5 / 8)$ & $88 \%(7 / 8)^{*}$ \\
\hline 28 day patency rate & NA & NA & $88 \%(7 / 8)$ & $78 \%(6 / 8)$ & $75 \%(6 / 8)$ \\
\hline
\end{tabular}

$p<0.05$ vs. Bare and Denucleated grafts.

Prox. graft

Mid. graft

Dist. graft

EPC
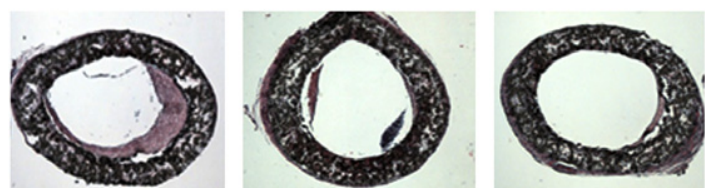

EPC+
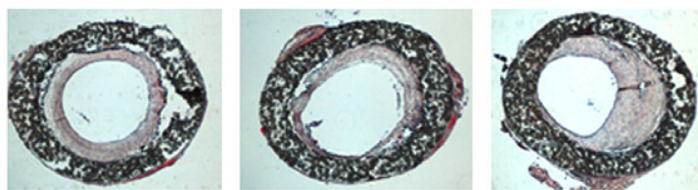

EPC+
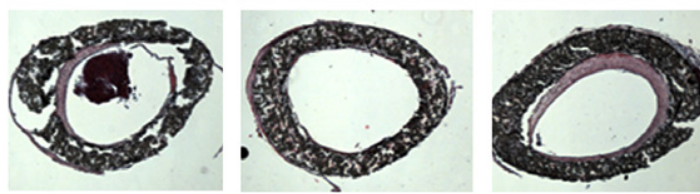

Fig. 4. Representative serial cross-sections of EPC-sodded grafts at the proximal, middle and distal graft regions.

EPC + AdCV grafts $(p<0.05)$. The distal regions of the grafts had the greatest hyperplasia response followed by the proximal region.

\subsection{EC staining}

Fig. 6 shows that confluent layers ECs remained present on the lumen of EPC + AdTM sodded grafts after 7 and 28 days as visualized through vWF staining (see arrows). Native femoral artery also stained positively for vWF, whereas denucleated grafts showed no positive staining. Sodded grafts had vWF staining on the graft lumen and within the graft wall after both 7 and 28 days.

Finally, bare grafts were negative for human MHC-I staining (Fig. 7A) while grafts sodded with human EPCs showed positive staining for human MHC-I within the graft lumen after 7 (Fig. 7B) and 28 days (Fig. 7C and D). The 28 day images showed that the neointimal area was likely made up of rat-derived cells as human MHC-I staining was negative in the area of hyperplasia (Fig. 7D).

\section{Discussion}

Vascular graft endothelialization is well known to improve the patency of small diameter vascular grafts [4,5]. These and other studies, however, rely on harvesting autologous blood vessels or microvascular tissue, an invasive procedure that introduces donor site morbidity $[4,5,27]$. In contrast, EPCs can be isolated non-inva-
(A)
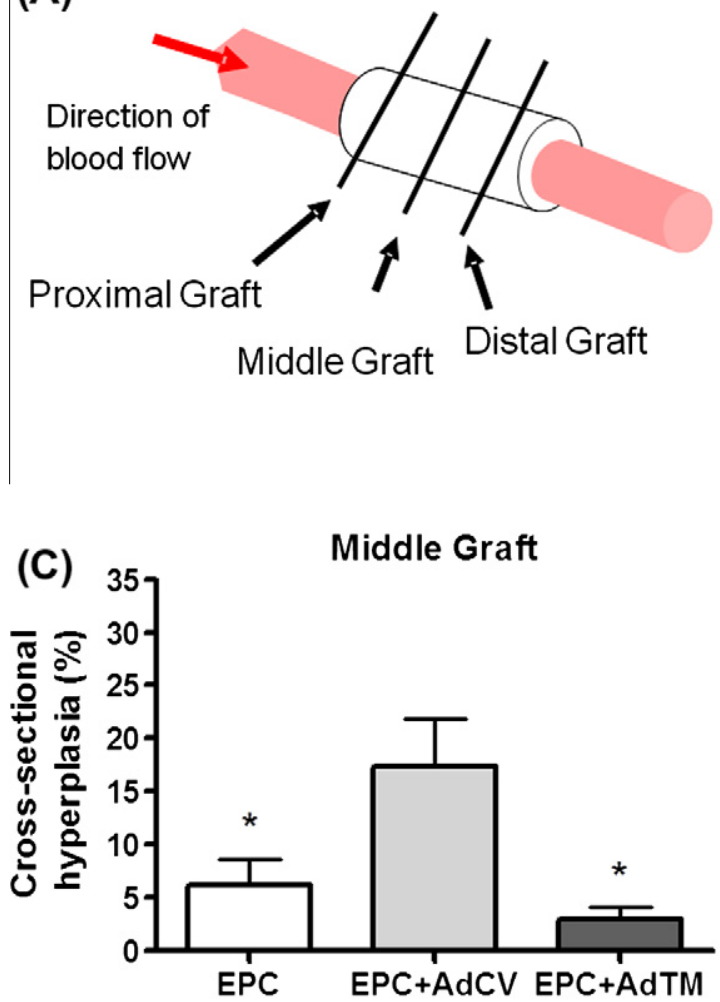

(B)
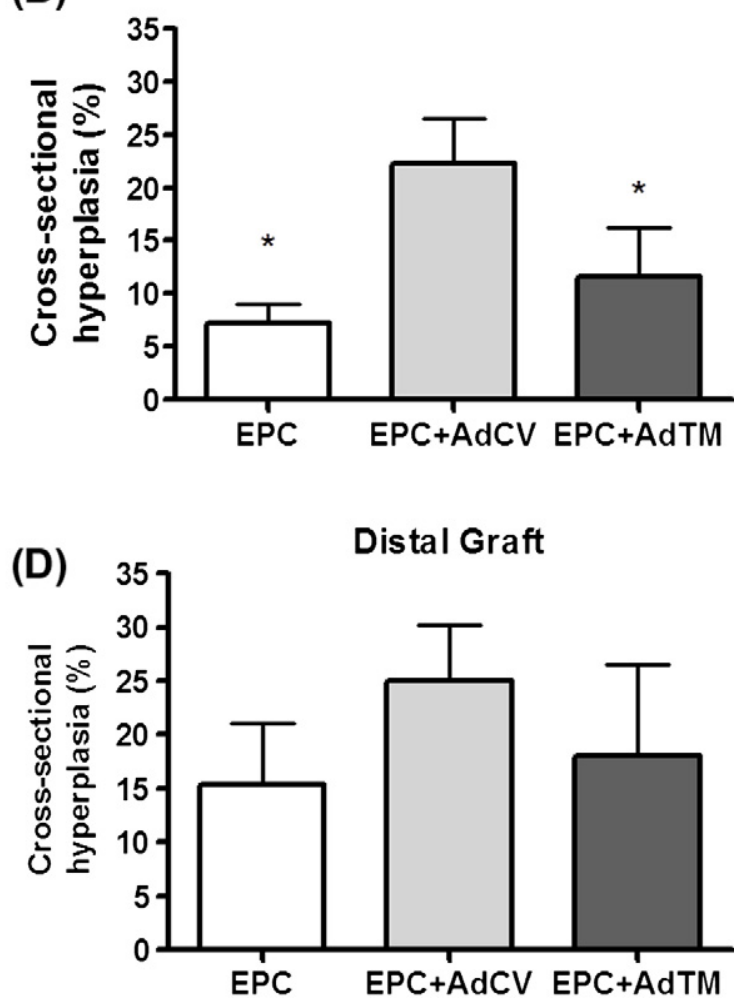

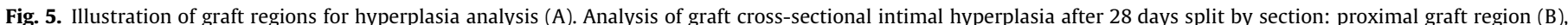
middle graft region (C) and distal graft region (D) $\left({ }^{*} p<0.05\right.$ vs. EPC + AdCV). EPC: $n=7 ; \mathrm{EPC}+\mathrm{AdCV}: n=6 ; \mathrm{EPC}+\mathrm{AdTM}: n=6$. 


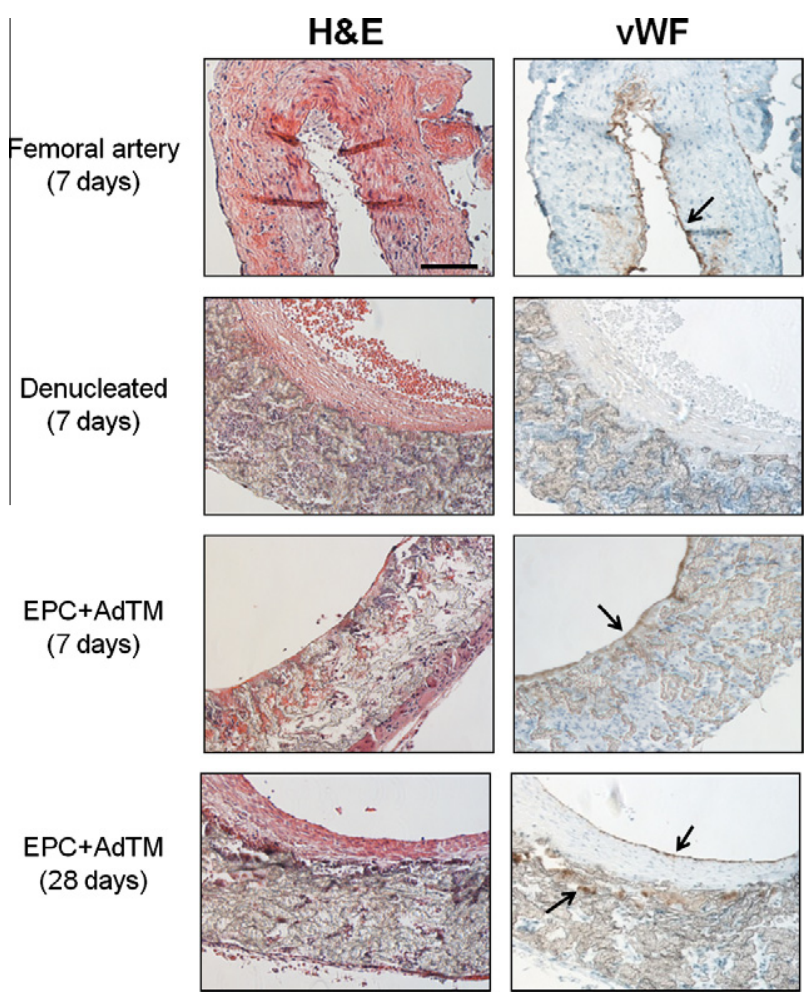

Fig. 6. $H \& E$ and vWF staining of the native rat femoral artery, denucleated graft and EPC + AdTM sodded graft at 7 and 28 days after implantation. Positive vWF staining (brown) is highlighted with arrows (scale bar $100 \mu \mathrm{m}$ ).

sively from samples of peripheral blood drawn from patients with documented CAD [11,28].

Previous studies using animal derived cells indicate that EPCs can improve the performance of synthetic vascular grafts [1214]. To date, however, only one study has tested the use of human blood-derived EPCs from healthy volunteers on vascular grafts in vivo [29]. Of course, healthy volunteers are not the target popu- lation for this therapy; rather, it is patients with significant CAD. The goal of the present study was to assess the in vivo patency rates of small diameter vascular grafts endothelialized with EPCs derived from peripheral blood of patients with CAD.

Recently published in vitro testing showed that patient-derived EPCs overexpressing human TM exhibited increased APC production, reduced platelet adhesion and prolonged clotting times compared to untransfected EPCs [19]. Therefore, this study also assessed whether enhanced graft patency was achieved by transfecting patient derived EPCs with the human TM gene ex vivo prior to graft sodding.

EPCs transfected with AdTM expressed TM that was biologically active and increased the in vitro rate of graft APC production 4-fold relative to grafts endothelialized with native EPCs. APC production per graft luminal area was approximately $30 \%$ lower than APC production than on flat TCPS [19]. The 4-fold increase in APC production rate due to $\mathrm{TM}$ transfection was similar in magnitude to previous studies with TM-transfected vein graft segments $[20,21,30,31]$.

Bare off-the-shelf and bare denucleated ePTFE positive controls exhibited the expected unacceptably low patency rates after 7 days ( $2 / 8$ remained patent in both cases). Although removal of trapped air from vascular graft materials by denucleation can decrease clot formation in both small and large animals [24,32] and enhance cell adhesion in vivo [33], no difference in patency rates was observed between the two control groups after the 7 day testing. Control trials out to 28 days were not attempted.

Sodding the lumen of denucleated grafts with EPCs dramatically increased graft patency over the control grafts after 7 days and also maintained improved patency after 28 days. Only one graft failed in each of the experimental trials for native EPCs after 7 and 28 days, and for EPCs transfected with AdTM after 7 days, whereas two grafts failed in 28 day trials for EPCs transfected with AdTM or AdCV. Thrombus was the dominant luminal histological feature after 7 days, while intimal hyperplasia was the dominant feature after 28 days, particularly at the proximal and distal peri-anastomotic regions.

Evidence that sodded human cells remained adherent 28 days after implantation was obtained from graft endothelium that
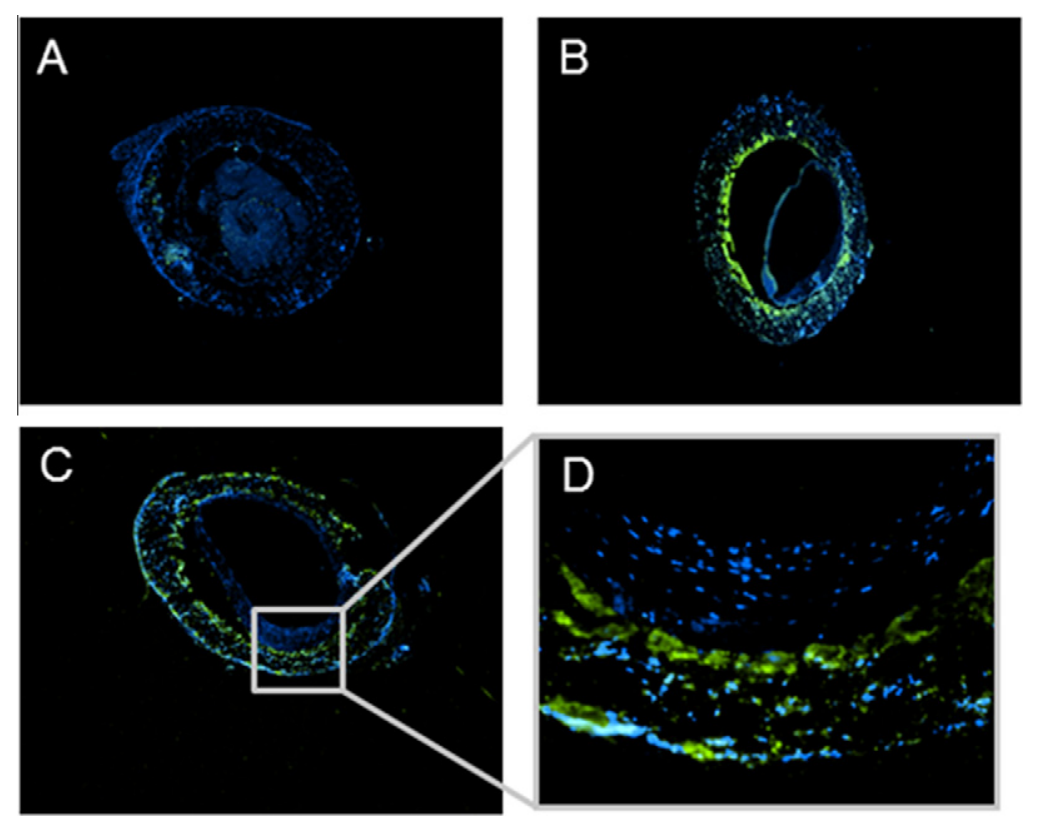

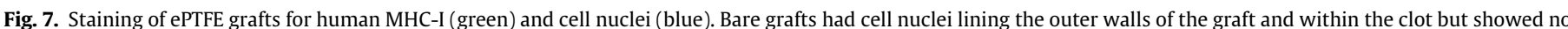

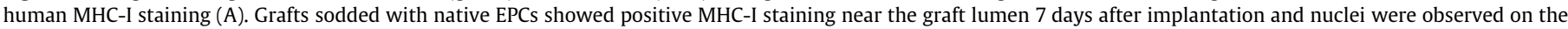
lumen and within the graft wall (B). After 28 days, sodded human EPCs remained on the graft original ePTFE lumen but not on the region of hyperplasia (C and D). 
stained positive for vWF - which was not specific for human or rat - and also stained positive for human specific MHC-I. However, regions of intimal hyperplasia that stained positively for vWF were negative for human MHC-I. We speculate that ECs in the hyperplasia regions may be of rat origin rather than the originally sodded human EPCs. The migration of ECs from the anastomosis is commonly observed in vivo, and is more pronounced in animal models than in humans [34]. It unlikely that the rat ECs were derived from circulating EPCs [35], or from ECs from migrating through the graft wall as the ePTFE graft material utilized in the present study was low porosity [36].

Overall, native and TM-transfected EPC sodded grafts had lower levels of thrombus formation and intimal hyperplasia compared to EPCs transfected with the control vector; however, there were no significant differences in either case between the native and TM-transfected EPCs groups. This observation differed from previous in vivo studies where autologous vein graft overexpression of TM reduced thrombosis $[20,21]$ and intimal hyperplasia [21].

In spite of in vitro evidence to the contrary, it was surprising that TM-transfected EPCs had no further benefit than native EPCs in increasing patency and reducing both thrombus formation and intimal hyperplasia. We offer the following possible explanations for this unexpected finding.

First, vector concentration was optimized in vitro for human EPCs, balancing cell death with robust TM expression; however, our previous studies also showed that adenovirus-transfected EPCs had lowered proliferation potential after transfection [19].

Second, in vitro characterization studies showed that TM upregulation lasted for only 1 week before returning to the basal level [19], indicating that longer durations of TM expression may be necessary to reduce intimal hyperplasia.

Third, TM-mediated anti-thrombotic activity may have been suppressed in vivo due to the differences in human TM activity compared to the rat coagulation substrates. Human TM is capable of binding rat thrombin and accelerating the conversion of human protein C to APC (data not shown). It remains unknown, however, whether human TM bound to rat thrombin can accelerate the activation of rat protein C. Pig TM, for example, activates human protein $C$ at only $10 \%$ of the rate of human TM [37]. Roussel et al. [37] suggested that the positioning and conformation of the pig TM active site may not be optimal for interacting with bound human protein C. Additional studies using human TM in rats showed that soluble human TM was capable of binding thrombin but was unable to activate rat protein $C$ [38]. This study was limited by the lack of commercial availability for rat protein $\mathrm{C}$. That withstanding, it is important to note that human TM overexpression has been used in rat [31] and rabbit $[20,21]$ studies, and showed a reduction in thrombus [20,21,31] and intimal hyperplasia [21].

Fourth, blood flow dynamics may have contributed to intimal hyperplasia that countered the effect of TM over expression. As blood travels from the native femoral artery into a graft of larger diameter, the expansion in lumen diameter decreases blood velocity, which can result in eddy formation and recirculating flow. This disturbed blood flow is often found at the vascular anastomosis, and is widely acknowledged to contribute to intimal hyperplasia (reviewed by Chiu and Chien [39]). Furthermore, laminar fluid flow increases the expression of the TM transcription factor KLF-2 [40], whereas disturbed flow suppresses KLF-2 expression and other anti-thrombotic and anti-cell proliferation molecules such as endothelial nitric oxide synthase [41,42].

Finally, intimal hyperplasia was observed at both proximal and distal sites. While hyperplasia is most common at the distal anastomosis, hyperplasia at the proximal anastomosis may have been due to recirculating flow. Computational simulations with an idealized geometry (detailed in the Supplement Information) indi- cated the presence of proximal recirculating flow during the diastole portion of the heart cycle. In agreement with prior studies modeling microvascular anastomoses, recirculation may have been a major contributor to the observed proximal hyperplasia [43].

The athymic rat femoral artery model was employed to allow the testing of human EPCs in a rodent model with relatively straightforward microsurgical access. The model provided lowered flow rates than an abdominal aortic interpositional graft, and therefore is a more stringent test of patency. Future studies require in vivo testing in a large animal model that can more closely mimic the geometry and flow rates of bypass grafts used clinically.

\section{Conclusions}

In this study we have shown that patient-derived endothelial cells, called EPCs, can be isolated noninvasively from small samples of peripheral blood, expanded to higher cell densities, and sodded onto the lumen of small diameter grafts to enhance graft patency in a thrombotic animal model. While TM overexpression improved graft performance vs. EPCs transfected with a control vector, there was no observed difference between native untransfected and TMtransfected EPCs. Thus, untransfected EPCs may be sufficient to improve the patency of small diameter vascular grafts. The use of untransfected EPCs also limits the risk of pre-existing immunity and the development of adaptive immune responses against viral proteins produced due to the adenoviral vector [43]. These results should encourage testing of EPCs in larger animal models with more physiologically relevant geometries and flow profiles.

\section{Acknowledgements}

These studies were supported in part by NIH grant HL044972 (W.R.), T32 GM8555 (J.S.) and the Robert Jones Fund (B.K.). The technical assistance from Nabila Haque and Julia Skettinifor are greatly acknowledged. We would also like to thank Steve Wallace and Ji Zhang for discussions regarding the computational modeling studies.

\section{Appendix A. Figures with essential colour discrimination}

Certain figures in this article, particularly Figures 2 and 4-7, are difficult to interpret in black and white. The full colour images can be found in the on-line version, at doi:10.1016/j.actbio.2011. 09.002 .

\section{Appendix B. Supplementary data}

Supplementary data associated with this article can be found, in the online version, at doi:10.1016/j.actbio.2011.09.002.

\section{References}

[1] MEMBERS WG, Lloyd-Jones D, Adams RJ, Brown TM, Carnethon M, Dai S, et al. Executive summary: heart disease and stroke statistics-2010 update. Circulation 2010;121:948-54.

[2] Canver CC. Conduit options in coronary artery bypass surgery. Chest 1995;108:1150-5.

[3] Weintraub WS, Jones EL, Craver JM, Guyton RA. Frequency of repeat coronary bypass or coronary angioplasty after coronary artery bypass surgery using saphenous venous grafts. Am J Cardiol 1994;73:103-12.

[4] Laube H, Duwe J, Rutsch W, Konertz W. Clinical experience with autologous endothelial cell-seeded polytetrafluoroethylene coronary artery bypass grafts. J Thorac Cardiovasc Surg 2000;120:134-41.

[5] Meinhart JG, Deutsch M, Fischlein T, Howanietz N, Fröschl A, Zilla P. Clinical autologous in vitro endothelialization of 153 infrainguinal ePTFE grafts. Ann Thorac Surg 2001;71:S327-31.

[6] Seifalian AM, Tiwari A, Hamilton G, Salacinski HJ. Improving the clinical patency of prosthetic vascular and coronary bypass grafts: the role of seeding and tissue engineering. Artif Organs 2002;26:307-20. 
[7] Lin Y, Weisdorf DJ, Solovey A, Hebbel RP. Origins of circulating endothelial cells and endothelial outgrowth from blood. J Clin Invest 2000;105:71-7.

[8] Ingram DA, Mead LE, Tanaka H, Meade V, Fenoglio A, Mortell K, et al. Identification of a novel hierarchy of endothelial progenitor cells using human peripheral and umbilical cord blood. Blood 2004;104:2752-60.

[9] Abou-Saleh H, Yacoub D, Theoret J-F, Gillis M-A, Neagoe P-E, Labarthe B, et al. Endothelial progenitor cells bind and inhibit platelet function and thrombus formation. Circulation 2009;120:2230-9.

[10] Allen JB, Khan S, Lapidos KA, Ameer GA. Toward engineering a human neoendothelium with circulating progenitor cells. Stem Cells 2010;28:318-28.

[11] Stroncek JD, Grant BS, Brown MA, Povsic TJ, Truskey GA, Reichert WM. Comparison of endothelial cell phenotypic markers of late-outgrowth endothelial progenitor cells isolated from patients with coronary artery disease and healthy volunteers. Tissue Eng Part A 2009;15:3473-86.

[12] Kaushal S, Amiel GE, Guleserian KJ, Shapira OM, Perry T, Sutherland FW, et al. Functional small-diameter neovessels created using endothelial progenitor cells expanded ex vivo. Nat Med 2001;7:1035-40.

[13] Griese DP, Ehsan A, Melo LG, Kong D, Zhang L, Mann MJ, et al. Isolation and transplantation of autologous circulating endothelial cells into denuded vessels and prosthetic grafts: implications for cell-based vascular therapy. Circulation 2003;108:2710-5.

[14] He H, Shirota T, Yasui H, Matsuda T. Canine endothelial progenitor cell-lined hybrid vascular graft with nonthrombogenic potential. J Thorac Cardiovasc Surg 2003;126:455-64

[15] Esmon CT. The roles of protein $C$ and thrombomodulin in the regulation of blood coagulation. J Biol Chem 1989;264:4743-6.

[16] Esmon CT. The protein C pathway. Chest 2003;124:26S-32S.

[17] Fujiwara Y, Tagami S, Kawakami Y. Circulating thrombomodulin and hematological alterations in type 2 diabetic patients with retinopathy. J Atheroscler Thromb 1998;5:21-8.

[18] Laszik ZG, Zhou XJ, Ferrell GL, Silva FG, Esmon CT. Down-regulation of endothelial expression of endothelial cell protein $C$ receptor and thrombomodulin in coronary atherosclerosis. Am J Pathol 2001;159:797-802.

[19] Stroncek JD, Xue Y, Haque N, Lawson JH, Reichert WM. In vitro functional testing of endothelial progenitor cells that overexpress thrombomodulin. Tissue Eng Part A 2011;17:2091-100.

[20] Waugh JM, Yuksel E, Li J, Kuo MD, Kattash M, Saxena R, et al. Local overexpression of thrombomodulin for in vivo prevention of arterial thrombosis in a rabbit model. Circ Res 1999;84:84-92.

[21] Waugh JM, Li-Hawkins J, Yuksel E, Kuo MD, Cifra PN, Hilfiker PR, et al. Thrombomodulin overexpression to limit neointima formation. Circulation 2000; $102: 332-7$

[22] Broxmeyer HE, Srour E, Orschell C, Ingram DA, Cooper S, Plett PA, et al. Cord blood stem and progenitor cells. Methods Enzymol 2006;419:439-73.

[23] Kidd KR, Patula VB, Williams SK. Accelerated endothelialization of interpositional 1-mm vascular grafts. J Surg Res 2003;113:234-42.

[24] Bensen C, Vann R, Koger K, Klitzman B. Quantification of gas denucleation and thrombogenicity of vascular grafts. J Biomed Mater Res 1991;25:373-86.

[25] Wigod MD, Klitzman B. Quantification of in vitro endothelial cell adhesion to vascular graft material. J Biomed Mater Res 1993;27:1057-62.

[26] Cheng C, Helderman F, Tempel D, Segers D, Hierck B, Poelmann R, et al. Large variations in absolute wall shear stress levels within one species and between species. Atherosclerosis 2007;195:225-35.
[27] Ahlswede K, Williams S. Microvascular endothelial cell sodding of 1-mm expanded polytetrafluoroethylene vascular grafts. Arterioscler Thromb Vasc 1994; $14: 25-31$

[28] Guven H, Shepherd RM, Bach RG, Capoccia BJ, Link DC. The number of endothelial progenitor cell colonies in the blood is increased in patients with angiographically significant coronary artery disease. J Am Coll Cardiol 2006;48:1579-87.

[29] Shirota T, He H, Yasui H, Matsuda T. Human endothelial progenitor cell-seeded hybrid graft: proliferative and antithrombogenic potentials in vitro and fabrication processing. Tissue Eng 2003;9:127-36.

[30] Kim AY, Walinsky PL, Kolodgie FD, Bian C, Sperry JL, Deming CB, et al. Early loss of thrombomodulin expression impairs vein graft thromboresistance: implications for vein graft failure. Circ Res 2002;90:205-12.

[31] Tabuchi N, Shichiri M, Shibamiya A, Koyama T, Nakazawa F, Chung J, et al. Nonviral in vivo thrombomodulin gene transfer prevents early loss of thromboresistance of grafted veins. Eur J Cardiothorac Surg 2004;26:995-1001.

[32] Vann RD, Ritter EF, Plunkett MD, Wyble Jr CW, Bensen CV, Gerth WA, et al Patency and blood flow in gas denucleated arterial prostheses. J Biomed Mater Res 1993;27:493-8.

[33] Pektok E, Cikirikcioglu M, Tille JC, Kalangos A, Walpoth BH. Alcohol pretreatment of small-diameter expanded polytetrafluoroethylene grafts: quantitative analysis of graft healing characteristics in the rat abdominal aorta interposition model. Artif Organs 2009;33:532-7.

[34] Zilla P, Bezuidenhout D, Human P. Prosthetic vascular grafts: wrong models wrong questions and no healing. Biomaterials 2007;28:5009-27.

[35] Hagensen MK, Shim J, Thim T, Falk E, Bentzon JF. Circulating endothelial progenitor cells do not contribute to plaque endothelium in murine atherosclerosis. Circulation 2010;121:898-905.

[36] Davids L, Dower T, Zilla P. The lack of healing in conventional vascular grafts. In: Zilla $\mathrm{P}$, Greisler $\mathrm{H}$, editors. Tissue engineering of prosthetic vascular grafts. Austin, TX: RG Landes Company; 1999. p. 3-44.

[37] Roussel JC, Moran CJ, Salvaris EJ, Nandurkar HH, d'Apice AJ, Cowan PJ. Pig thrombomodulin binds human thrombin but is a poor cofactor for activation of human protein C and TAFI. Am J Transplant 2008;8:1101-12.

[38] Takahashi Y, Hosaka Y, Imada K, Adachi T, Niina H, Mochizuki H. Species specificity of the anticoagulant activity of human urinary soluble thrombomodulin. Thromb Res 1998;89:187-97.

[39] Chiu J-J, Chien S. Effects of disturbed flow on vascular endothelium: pathophysiological basis and clinical perspectives. Physiol Rev 2011;91:327-87.

[40] Dekker RJ, van Soest S, Fontijn RD, Salamanca S, de Groot PG, VanBavel E, et al Prolonged fluid shear stress induces a distinct set of endothelial cell genes, most specifically lung Kruppel-like factor (KLF2). Blood 2002;100:1689-98.

[41] Wang N, Miao H, Li Y-S, Zhang P, Haga JH, Hu Y, et al. Shear stress regulation of Krüppel-like factor 2 expression is flow pattern-specific. Biochem Biophys Res Commun 2006;341:1244-51.

[42] Cheng C, van Haperen R, de Waard M, van Damme LCA, Tempel D, Hanemaaijer L, et al. Shear stress affects the intracellular distribution of eNOS: direct demonstration by a novel in vivo technique. Blood 2005;106:3691-8.

[43] Zaiss AK, Machado HB, Herschman HR. The influence of innate and preexisting immunity on adenovirus therapy. J Cell Biochem 2009;108:778-90. 